\title{
Teacher Experiences and Perceptions of Collaboration and Peer Support \\ in an Innovative Learning Hnvironment
}

DOI: 10.47050/66515321.150-169

Louise Campbell

The research under discussion here was part of a larger project to investigate teaching and learning in a newly created innovative learning environment in an otherwise traditional secondary school in Central Scotland. By focussing on interview data gathered in relation to collaboration, peer observation and the realities of sharing a large teaching space, as experienced by the participants, this discussion explores what collaborative working entails for the teachers within the context of this project. Planned culture shifts, where teachers have been asked to teach using new strategies in a new and unfamiliar learning space, make emotional as well as pedagogical and practical demands on teachers. It is argued in this paper that the adaptation of practice required by teachers in such spaces makes it an intimidating prospect for some. The implications these findings may have for teacher education and for the support of practising teachers to help them engage in effective peer collaboration are also explored.

\section{Keywords:}

innovative learning environment

teacher collaboration

teacher education policy

teacher professional development 


\section{Introduction}

Collaborative working is a term that is increasingly pervasive in employment contexts, and one that is becoming prevalent in education too, in recognition of the requirement for formal education systems to prepare young people for the intellectual rigours and complex social expectations of the workplace (Fletcher et al., 2018; Griffin et al., 2012; Holocher-Ertl et al., 2011). Collaborative working is associated with shared thinking with the benefit of combined knowledge and experience. This combinatory characteristic can catalyse creative and innovative problem solving (Craft, 2008; Graesser et al., 2017) and is seen as a desirable and effective way of meeting the challenges of the rapidly changing contexts for work that are the inevitable consequence of technological proliferation (Levi, 2010). It is, in other words, an important competence expected of those entering the workforce. As a consequence, it is a focus of interest for education systems with "process" curricula that seek to prioritise the development of skills over the accumulation of knowledge.

Teacher collaboration has been raised as one route to helping school age learners to build these desirable skills (Baepler \& Walker, 2014; Rytivaara \& Kershner, 2012). There are numerous advantages to teacher collaboration for educators. These include opportunities for professional development (Rytivaara \& Kershner, 2012), reduced feelings of isolation and a heightened sense of engagement with the immediate professional community (Thousand et al., 2006). In their systematic review of 82 studies, Vangrieken, Dochy, Raes and Kynd (2015) found that there were a wide range of additional positive outcomes associated with teachers' collaboration, including increased motivation, improved efficiency, more frequent innovation and the enhancement of professional and technological skills. Clearly, then, collaborative working has much to offer the teaching community.

Yet, in practice, collaborative working amongst teachers remains a work in progress in schools, particularly in relation to the practice of teaching, where a sense of workplace isolation has been cited as a significant cause of teachers leaving the profession (Altieri et al., 2015; Buchanan et al., 2013; Heider, 2005; Paris, 2013). One of the reasons for this may be that collaborative teaching entails the development of a democratic approach to shared responsibility and accountability (Jones et al., 2008) that can cause a measure of cognitive dissonance 
for teachers who have become used to exclusive control over their planning and decision-making. Autonomy and the opportunity to take individualistic and creative approaches to the work of teaching are, it could be argued, key benefits of the job. Another reason may be the structural barriers created by complex timetables and competing workload pressures (Thousand et al., 2006). Human conflict is also a factor that cannot be ignored, with competitiveness and perceived inequities (Vangrieken et al., 2015) impacting teacher motivation to engage with peer collaboration. The tension between apparent benefits and structural barriers is one that has yet to be successfully resolved.

Efforts to encourage teacher education to make moves in the direction of increased professional co-operation and collaboration have aimed to present this as a professional skill that should be amongst the core competences demonstrated by new teachers entering the profession. For example, a key message outlined in the Donaldson Review of teacher education in Scotland (2011) was that teacher professionalism should involve the ability "to work in partnership with other professionals; and to engage directly with well-researched innovation" (ibidem, p. 19). This implies not only engagement with others beyond the school setting but also collaboration with those within it, in order to best meet the needs of learners. The matter of innovation is one that raises a number of further queries. Does this mean innovative pedagogy? New technologies for learning? A need for ongoing experimentation with practice? It is possible that the vagueness of this statement in the Donaldson Review is a deliberate choice to encourage educators to open themselves up to change and professional development in the broadest sense, across the many possible contexts in which educators may find themselves.

One form of innovation, increasingly prevalent in Scottish schools and elsewhere, is the innovative learning environment. The layout of innovative learning environments, which are often larger than standard classrooms, adaptable and digitally connected, is allied with the expectation that they will be used as collaborative spaces for both teaching and learning (OECD, 2013). Scottish education policy advocates for the development of such spaces as part of providing a solid foundation for a curriculum that is designed to facilitate increased learner engagement and thereby, it is implied, higher 
attainment: "Teachers need access to learning spaces which can meet a multiplicity of purposes, for example, whole class teaching, collaborative group work, paired working and independent research based work" (The Scottish Government, 2007, p. 8).

This perceived need for spaces with flexibility to meet a range of purposes has encouraged the development of school designs where the nature of the architecture is seen as an integral part of shaping not only practical matters of usage but also altering pedagogical thinking. "School buildings and facilities are far more than just part of the supporting case for Curriculum for Excellence [the Scottish curriculum for children aged 3-18]. They are at the heart of the whole philosophy and approach to effective learning and teaching and play the fullest part in helping to achieve change for the better" (The Scottish Government, 2009, p. 25).

In other words, school building design is regarded as being not only integral to promoting the curriculum drivers underlying practice in education but also, at least in part, constitutive of them, in the sense of enabling a change in the perceptions of what schools can and should do. The creation of flexible spaces labelled "innovative" or "inspiring" could be seen as an attempt to engage teachers in a process of re-evaluating their practice. It is, as yet, unclear whether these objectives have been meaningfully achieved, though there are a number of studies and research agendas emerging which endeavour to explore precisely this question (Campbell, 2020; Cleveland, 2018; Young et al., 2019). Given the level of financial investment in the creation of these spaces, it could be argued that this research agenda is somewhat overdue.

The research under discussion here was part of a larger project to investigate teaching and learning in a new innovative learning environment in an otherwise traditional secondary school in Central Scotland. By focussing on data gathered in relation to collaboration, peer observation and the realities of sharing a large teaching space, as experienced by the participants, these are explored to identify and examine what working in partnership and engaging directly with innovation entails for these teachers within the context of this project. The implications these findings may have for teacher education and for the support of practising teachers to help them engage in effective peer collaboration are also explored. 
The question guiding this part of the research and the discussion that follows here concerns the participating teachers' experiences and perceptions of collaborative teaching and peer support while working in an innovative learning environment. The intention was to see whether the collaborative intentions of the spatial design were being realised in practice.

\section{The Context of the Study and the Methods Employed}

This research took place in a medium-sized secondary school in Scotland. The school is located in a moderately affluent catchment that is mainly suburban but partly rural in character. The Local Authority bid for funding to create an innovative learning environment and was awarded this funding by the Scottish Government. The motivation for the creation of the space was to enable teachers and learners to explore and experiment with alternative pedagogies and structures for learning as preparation for moving into a new school building that was designed with open, large and flexible spaces, in keeping with the demands of the Curriculum for Excellence (Education Scotland, 2020) and the growing perception that schools need to reflect structural elements of the workplace and help to build the skills that are needed there (The Scottish Government, 2007). The wider purpose of the research was to understand whether or not the innovative learning environment was successfully fulfilling this objective (Campbell, 2020).

The innovative learning environment consisted of three standard-sized classrooms that were opened up to create one large space, where up to 100 pupils could be accommodated at a time. The space was equipped with mobile and flexible furniture, interactive screens and whiteboard walls. The intentions underlying this were to enable the space to be as adaptable as possible to meet the range of teaching and learning needs that might be required by the variety of subjects and departments in the school.

Taking the view that teachers' practice reflects not only their location within particular social, cultural and policy-related situations (Day, 2012; Osborn \& McNess, 2005; Priestley, 2011) but also their uniquely personal perceptions and influences (Beijaard et al., 2000; Campbell, 2019), this investigation took the view that participants would be able to share some sense of their beliefs and insights in relation to working in the innovative learning environment. The perspectives of the participants discussed 
here are considered as representations of experience and thought; inherently subjective but unique and valuable for exactly this reason. While there was no expectation of being able to draw definitive truths from this process, it was hoped that the choices these teachers had made in relation to working in the space, and the reasons they provided for these, would enable a better understanding of the ways in which the space was (or was not) meeting the objectives claimed for it.

One-to-one interviews were undertaken with six teaching staff who volunteered to participate. These participants had a variety of levels of experience of using the new learning space, which had been open for use for almost a full academic year at the time of the interviews. Two of the interviewees had chosen not to be engaged with the space at all. It was considered valuable to explore their reasons for this in order to better understand how to make the space more appealing to teachers who were not using it, as well as to gain an understanding of what the barriers to use were for these teachers. The participants had varying levels of experience in teaching and were teachers of a range of secondary school subjects. Two had been in the teaching profession for fewer than five years. Where extracts from transcripts have been shared, participants' names have been pseudonymised.

Qualitative analysis, utilising inductive strategies to develop and categorise thematic strands within the data, offered opportunities to recognise and value the experiences and thoughts shared by participants. A primary cycle of coding was undertaken to identify core ideas and concerns. This was followed by a secondary coding cycle to draw these together into themes. Four interrelated themes emerged in relation to participants' perceptions of collaboration and peer support in the new learning space. These were (1) planning, (2) control, (3) relationships with learners and (4) visibility. These four themes have been used as stimuli for the exploratory and theoretical discussion that follows here.

\section{Planning for Collaborative Teaching and Learning}

Jack: You hear about interdisciplinary learning and you think, "what an opportunity for a group of geographers, a group of biologists and a group of history students to come together", but I just think that the actual planning behind that is what puts teachers off doing it. 
The issue of planning and the level of detail involved with this (along with the time that such planning would be likely to take) was a clearly identified preventative to collaborative teaching amongst the interviewees. In Jack's transcript extract above, the focus is given to the potential for interdisciplinary learning offered by the space, seeing in the abstract the scope that a large, flexible space could offer for undertaking this kind of learning. However, the scope and scale of the thought that would be needed to enable this collaborative effort to happen is regarded as a significant barrier.

It is possible this may be less a concern related to the space than one that is connected with the implicit border-policing around subject areas that helps to define secondary school teachers' work (Fox, 2010; Hobbs, 2012; Savage, 2012) and the process of their assimilation into the teaching profession at the beginning of their careers (Archer et al., 2012; Fisher \& Webb, 2006; Kyriacou \& Kunc, 2007). Secondary school teachers in Scotland, and many other countries, are qualified as a minimum to degree level in a specialist subject and qualify to teach in this area of specialism. As a result, they see this as part of their professional identity. A lack of confidence in engaging with other disciplines and areas of the curriculum, even with the benefit of colleagues' expertise, presents a cognitively challenging picture, which, when compounded with other challenges such as time constraints and other professional pressures, results in resistance and/or avoidance (Brand \& Triplett, 2012).

The roots of this resistance may also be linked with teachers' memories of the detailed and complex lesson planning required of student teachers, where this becomes a hugely time-intensive aspect of initial teacher education. Lesson planning is seen as vital to professional growth and developing good habits for practice during the period when student teachers are learning the curriculum, the requirements of their subject areas and the pedagogical strategies that support effective learning (John, 2006; Santoyo \& Zhang, 2016). As teachers become more experienced, their planning takes a more abbreviated form. There is a reliance on pedagogical content knowledge, where previous iterations of successful lessons, a recognition of what creates the conditions for effective learning, and the confidence that comes from having ready teaching resources contribute to less time being required for lesson planning (Park \& Oliver, 2008). The prospect 
of returning to the "novice" state, where experience and expertise around some of these areas can no longer be relied upon, is one which understandably appears to have limited appeal.

If it is desirable for teachers to overcome these barriers to extend their professional learning and pedagogical range, then the question becomes one about how this can be more effectively scaffolded to make it manageable, practical and appealing for the teachers involved (Musanti \& Pence, 2010). The hidden barriers to undertaking this kind of collaborative, interdisciplinary work, which is a fundamental concern of education policies and curricula that seek to engage teachers in these strategies, need to be explicitly addressed. There are examples of successful approaches at work internationally (see Havnes, 2009; Stolle \& Frambaugh-Kritzer, 2014) from which lessons might usefully be learnt. These include strategies for educating student teachers via interdisciplinary projects and enabling practising teachers to maintain their individuality and autonomy whilst working within discursive professional communities. These strategies enable teachers to co-operate and share their thinking and motivations as part of their professional learning.

\section{Surveillance, Control and the Challenge to Leadership}

\section{Kira: I said, "How about we do this in the learning space together?" \\ And then before I shut my mouth, I opened it again and said, "No. Forget that", because I remembered the behavioural issues between the two classes. We put them together before and it was horrific.}

For most of the interviewees who had made use of the space, this was confined to booking the space for their own class and using the facilities as appropriate to complement traditional classroom learning. Although the question of collaborative teaching had been raised with colleagues, where this had been considered, it had generally been discounted as unmanageable or impractical, as the extract from Kira's interview transcript above suggests. In Kira's case, there had at least been a previous attempt at collaborative teaching, though by implication it was not a positive experience and was sufficiently 
problematic to dissuade Kira from trying this approach with her colleague a second time.

The matter of classroom control and behaviour management was a conspicuous consideration raised by interviewees. In spite of studies that have shown the value of team teaching for managing students' behaviour (Hayden \& Pike, 2005), the familiar confines of the conventional classroom environment were argued by participants in the present research to offer behavioural benefits in terms of the habitual routines in place in these settings. Moving into a larger, less formal space, with other classes and their different rules and routines, offers the potential for confusion and a variety of associated challenges (physical, social and emotional). The size and shape of the innovative learning space, with areas that made supervision difficult, was considered by some to be unmanageable, though this was not always considered by the interviewees in the context of more than one pair of eyes, where responsibility for behaviour management could be shared. This could be regarded as a consequence of a lack of experience with collaborative practice.

In their explanations about concerns relating to surveillance and control within the space, interviewees seemed to consider their leadership would be compromised. This suggests that shared or distributed leadership was a difficult concept for these teachers to embrace. This is in line with the challenges that have been identified elsewhere (Firestone \& Martinez, 2007; Lahtero et al., 2017; Robinson, 2008). There are issues of workplace culture at play in this context. If conceptions of leadership are tied to single sources of authority, this makes it understandably difficult to conceptualise or create space for shared or team leadership.

As Kira's transcript extract implies, there is also a challenge around the interrelationships between pupils across classes. One of the assumptions guiding the creation of open, flexible spaces for learning is that learners' identities are fluid and able to move between individual and group learning experiences seamlessly, provided there is the right infrastructure and support. However, this perspective does not take into account the idea of classes forming their own social identities (McManus, 2010; Stets \& Burke, 2000) with associated allegiances and antipathies, distinct from other classes at the same age and stage. There can be no simple equation that two classes studying 
the same subject in the same place at the same time will be able to do so without any difficulties. However, this is not to say that new social formations are not possible. Indeed, it is arguable that it is a crucial aspect of the planning process for collaborative teaching and learning to consider how to create bonds between the classes that are coming together for learning so that a new social identity can be formed for the particular purpose of working in a large collaborative space.

In the context of teachers working together, it becomes apparent that curriculum planning for teaching and learning under these circumstances is only one dimension of the necessary preparation required for collaborative practice of this kind (Altieri et al., 2015; Havnes, 2009; Jones et al., 2008; Musanti \& Pence, 2010). Consideration also needs to be given to the catalytic social and behavioural reactions that can take place between individual pupils, between groups of pupils or between pupils and less familiar teachers. The introduction of so many human variables, alongside the no less significant variable of the teaching space itself, creates a daunting prospect for teachers considering the possibility of working collaboratively in a shared and unfamiliar space, though it is by no means an insurmountable obstacle if these challenges are given due consideration as part of the planning process. The importance of valuing positive relationships between teachers and the individuals within their class was also raised as a theme in its own right.

\section{Relationships with Learners}

Jack: I like to have these twenty kids in front of me that I know well, rather than another twenty and another twenty that I do not. You know, it is all about relationships for me, so it is not about technology, and that is what you build up in that little [traditional classroom] area...

An intriguing theme that arose in the data is related to the importance of teacher-student relationships and concerns about the loss of these that might occur with a change in the composition of classes when engaging with collaborative practice in the innovative learning environment with colleagues. For Jack, who shared the comment above, teaching a practical subject, with the relatively small maximum 
class size of twenty entailed in that, is one of the significant benefits of practice. To enlarge the number of students requiring attention through the process of collaboration with other classes and their teachers is perceived to mean the dilution of the time and attention that can ordinarily be given by Jack to his own students. This is equated with an ensuing weakening of the positive relationships that have been built over time in the traditional classroom setting.

The emotional comfort and social strength to be drawn from working within the familiar patterns of interaction and expectation that guide the teacher-student relationship (Dooner et al., 2010) may offer an insight into the reasons for some teachers' lack of engagement with the innovative learning environment even on a solo basis and without the added complexity of teacher collaboration. The space itself, with its key characteristics of openness, flexibility and scale, makes it sufficiently alien to present an unnerving picture to those teachers who place a high pedagogical value on their personal interactions with students. The sense of anxiety is palpable in Jack's comment, where "another twenty and another twenty" are presented as a faceless phalanx of unknown students, distant and potentially overwhelming.

Considering this perspective as tightly tied to personal pedagogical principles raises the issue of how well the teachers who were interviewed understood or had engaged with the forms of pedagogy that are recognised as effective in this kind of space. It has been argued that by setting the student at the centre of her or his own learning, the potential arises to enable and embolden the student to develop autonomous approaches to learning and the intrinsic motivation to make progress with this (Lim et al., 2012). It has also been suggested that empowering the student in this way creates a more positive perception of the learning environment for students (Baepler et al., 2014), as well as contributing to an improved rapport between the students themselves (Baepler \& Walker, 2014). These outcomes are some of the central drivers for the development of flexible learning spaces. Collaborative teaching affords multiple sources of knowledge and skill for students (Little \& Hoel, 2011). It is also argued to provide an important working model of the collaborative skills that process-based curricula ask students to develop (Thousand et al., 2006). There is, therefore, a fundamental philosophical and pedagogical conflict at work here. If teachers' perceptions of the value of their personal and 
professional contribution to the learning process are directly challenged by flexible learning spaces, this becomes a difficult conflict to resolve.

It could be argued that these spaces should, rather, offer the opportunity for teachers to extend their pedagogical range, providing a locus for developing alternative and complementary strategies to support the learning process (Cleveland, 2018; Young et al., 2019). However, for this to be possible, there is a need for teachers to be offered professional development opportunities to enable them to understand the advantages for students and identify appropriate pedagogies to support effective and meaningful teaching and learning in such spaces. While this is not an issue directly related to collaboration, it is one that might be well supported by collaborative practice (Owen, 2015; Stewart, 2014) to enable more hesitant teachers to see effective practice in action or to enable them to experiment with different approaches and assess their learning outcomes.

\section{Visible Teaching and Visible Learning}

\section{Lana: There is a kind of culture in teaching that we have our classroom and we go in and we shut the door, whereas obviously the learning space is absolutely open, you know. There is nowhere to hide from the kids or from other colleagues.}

A sense of performing the work of teaching as a private practice in a private space is one that is implicit in Lana's interview transcript extract above. With a move into the inspiring learning space, the work of teaching becomes much more public, offering opportunities to see and be seen by colleagues as well as other students. While for some this may present a positive challenge, for others it creates a sense of vulnerability that is directly related to their lack of preparedness to engage with the space experimentally to see what affordances it may offer. For some of the participants, being seen while teaching in the innovative learning environment presented no discernible worries, but for others it was a source of anxiety. The potential for making "mistakes", being seen to be less than competent and moving away from the comfort of familiar practice was ample reason to avoid engaging with collaborative practice (or, indeed, any practice) in the space. 
Ironically, in a teaching environment that is designed to promote social interaction and collaborative engagement, this is an area of conflict. Although teaching is regarded as a profession which espouses the need for learning from mistakes, the practical work of teaching appears to be regarded by some teachers as exempt from this. Studies have suggested that, for pupils, seeing teachers modelling the process of learning and growth through their own professional behaviours is a very positive and influential learning process (Jones et al., 2008; Little \& Hoel, 2011; Thousand et al., 2006). However, the act of learning in front of learners may present difficulties for teachers' sense of their role as leaders of learning and the "more knowledgeable other" in the teacher/learner dyad.

The culture of teaching referred to in Lana's transcript extract is one which harks back to the transmission model of teaching, which remains a dominant model in some school contexts. In this version of teaching as a profession, the teacher is the prime source of information and therefore needs to be able to present an unassailably confident and knowledgeable persona. The version of the teaching professional that operates more successfully in innovative learning environments is one that is bound up, instead, with negotiation, a flexible, discursive disposition and openness to possibilities. These attributes are perhaps linked with the need for embracing professional vulnerability and experimental approaches to pedagogy in a collaborative space.

The implied issue raised by Lana's comment is one that has been examined in a number of theoretical explorations of the work of teaching, namely the challenges raised by cultures of performativity and the challenges of being at odds with the dominant discourses at work within the school ecology (Ball, 2003; Biesta, 2009). For teachers, there is a very real possibility that professional embarrassment and dishonour can arise from situations where peer observation is an unusual and unlooked-for dimension of practice.

However, there are varieties of professional culture where there is the conscious development of a much more empathetic and generous community of support (Kennedy, 2016; Owen, 2015). In supportive professional communities of this kind, there is a recognition of a shared continuum of professional development and the sense that there is room for growth for everyone. In these communities, interaction, sharing and observation are common features and ones which are 
regarded as normal. Collaborative practice is, in these situations, much more feasible and desirable, and also offers a suite of benefits for all members of the community. Concerns about loss of face, judgment and failure are not part of the discourse in this form of professional life because dialogues are focused on growth and development rather than outcomes or achievement. There is a need for the ethos underpinning such a community to be embedded in every level of the educational culture, from government, through education policy, to teacher education and through these into all tiers of practice in schools. Without this holistic approach, it is difficult to see how a wholesale engagement with collaborative teaching in spaces such as the innovative learning environment can come to fruition.

\section{Implications}

The aim of this paper was to examine the perspectives of teachers in relation to their willingness to collaborate with peers for teaching in an innovative learning environment. The discussion here has explored four interrelated themes that presented challenges to the participating teachers in their practice. The four themes - planning, control, relationships and visibility - are each significant fields of educational research focus in their own right and therefore offer much scope for further exploration. However, the unique context of the innovative learning environment has offered the opportunity to develop a richer insight into some of these issues, particularly with a view to exploring how best to support teachers in the pursuit of effective and confident collaborative practice in such spaces.

The principal practical implication of this study is that effective and meaningful collaborative teaching requires significant scaffolding and support on the part of teacher managers, local government and national policy makers. Theoretically speaking, the issues presented by the participants in this study suggest there is a significant gulf between the curriculum and policy drivers that seek to embrace collaborative working for teachers and the day to day experiences and perceptions of teachers themselves. There is, undoubtedly, scope for a more streamlined and coherent approach to engaging teachers in this kind of work.

Of the four themes that have been explored in this paper, three are "human" or psychological in nature. Concerns about behaviour 
control and harnessing the power of positive relationships to aid learning are implicitly connected and may be seen as apprehensions about maintaining the boundaries around the interactions and bonds between teachers and pupils within a designated space. In some senses, it is reassuring to know that these are considerations of import to teachers. The matter of teachers being placed in a position of unaccustomed visibility to peers during collaborative teaching and the vulnerability this creates in an unfamiliar space could also be seen as a matter of relationships, insofar as this is a challenge for teachers' sense of self-esteem and self-efficacy (Tschannen-Moran et al., 1998; Woolfolk \& Hoy, 1990). These are social in nature but created, at least in part, in response to either implicit or explicit feedback.

The remaining theme, planning, is one which appears to present teachers with challenges of a predominantly structural nature, with a dependence on teachers being provided with time and opportunity for this work to take place. However, there are also emotional dimensions relating to planning, where taking on the responsibility of working with others to plan collaborative teaching and doing so in ways that can be seen to be effective for learners may be regarded as requiring new and different skills from teachers to those involved with their customary lone practice. The process of planning collaboration opens up individuals' pedagogy, practice and efficacy to scrutiny, and therein lies a source of conflict, particularly in a working context where this kind of scrutiny is not a normal and accepted aspect of practice. In such a setting, it is difficult to escape the perception that peer scrutiny will come loaded with the emotionally hazardous experience of being subjected to peer evaluation and, even more disturbingly, negative judgements.

Taken together, these findings suggest the vital importance of a positive collaborative ethos built into every aspect of school culture. Culture shifts such as those seen in the context of this study, where teachers have been asked to teach in a new and unfamiliar learning space, make emotional as well as pedagogical and practical demands on teachers (Deed, 2015). As has been argued in this paper, the adaptation of practice required by teachers in such spaces (i.e. with the expectation of professional collaboration and visibility to teacher peers) makes it an intimidating prospect for some. There are also issues for teachers' sense of identity and their evaluation of their 
own purpose and role that need to be considered. It is clear that affect has micropolitical dimensions for teachers' practice (Mulcahy \& Morrison, 2017) and for their sense of professional autonomy (Charteris \& Smardon, 2019) that should not be overlooked by those seeking to make changes to teachers' practice and to break with traditional models of teaching. Arguably, by normalising collaboration and developing a culture of mutual support across all the diverse dimensions of teachers' practice, not only for teachers' work in innovative learning spaces, less anxiety about collaborative approaches to practice seems a likely outcome.

It would be remiss not to restate, at this closing stage of the discussion, that in addition to being sites of professional anxiety and personal vulnerability for some teachers, innovative learning environments need to be recognised as sites of policy actualisation that are directly related to managerialist discourses of productivity. Their purpose is to serve the economy by shaping the skills and habits of the future workforce (OECD, 2013; The Scottish Government, 2009; The Scottish Government, 2007). Consequently, there are much wider issues at stake here than those connected with teachers' engagement and choices in relation to their collaborative practice. There are questions here that relate to the spirit and philosophy that guide our beliefs and overarch our approaches to education as a whole. This being the case, there is much scope for further exploration in connection with the issues raised in this paper.

\section{References}

$\rightarrow$ Altieri, E. M., Colley, K. M., Daniel, L. S. and Dickenson, K. W. (2015). Merging Expertise: Preparing Collaborative Educators, The Rural Special Education Quarterly, 34(1), 17-22.

$\rightarrow$ Archer, R., Morgan, S. and Pope, S. (2012). Rethinking partnership in initial teacher education - developing professional identities for a new subject specialist team which includes a joint school-university appointment - a case study in mathematics, https://research.manchester.ac.uk/portal/en/ publications/rethinking-partnership-in-initial-teacher-education--developingprofessional-identities-for-a-new-subject-specialist-team-which-includes-ajoint-schooluniversity-appointment--a-case-study-in-mathematics(a53aac265f97-4f5c-8d2c-24174e8c1f6a)/export.html 
$\rightarrow$ Baepler, P. and Walker, J. D. (2014). Active Learning Classrooms and Educational Alliances: Changing Relationships to Improve Learning, New Directions for Teaching and Learning, 137, 27-40.

$\rightarrow$ Baepler, P., Walker, J. D. and Driessen, M. (2014). It's not about seat time: Blending, flipping, and efficiency in active learning classrooms, Computers \& Education, 78, 227-236.

$\rightarrow$ Ball, S.J. (2003), The teacher's soul and the terrors of performativity, Journal of Education Policy, 18(2), 215-228.

$\rightarrow$ Beijaard, D. D., Verloop, N. and Vermunt, J.D. (2000). Teachers' perceptions of professional identity: An exploratory study from a personal knowledge perspective, Teaching and Teacher Education, 16(7), 749-764.

$\rightarrow$ Biesta, G. J. (2009). Good education in an age of measurement: On the need to reconnect with the question of purpose in education, Educational Assessment Evaluation and Accountability, 21(1), 33-46.

$\rightarrow$ Brand, B. and Triplett, CF. (2012). Interdisciplinary curriculum: an abandoned concept?, Teachers and Teaching, 18(3), 381-393.

$\rightarrow$ Buchanan, J., Prescott, A., Schuck, S., Aubusson, P., Burke, P. and Louviere, J. (2013). Teacher Retention and Attrition: Views of Early Career Teachers, Australian Journal of Teacher Education, 38(3), 112-129.

$\rightarrow$ Campbell, L. (2019). Pedagogical bricolage and teacher agency: Towards a culture of creative professionalism, Educational Philosophy and Theory, 51(1), 31-40.

$\rightarrow$ Campbell, L. (2020). Teaching in an Inspiring Learning Space: an investigation of the extent to which one school's innovative learning environment has impacted on teachers' pedagogy and practice, Research Papers in Education, 35(2), 185-204.

$\rightarrow$ Charteris, J. and Smardon, D. (2019). Dimensions of Agency in New Generation Learning Spaces: Developing Assessment Capability, Australian Journal of Teacher Education, 44(7), 1-17.

$\rightarrow$ Cleveland, B. (2018). Why Innovative Learning Environments? Stories from three schools that helped establish an ongoing space and pedagogy agenda. In: S. Alterator, C. Deed (eds.), School Space and Its Occupation Conceptualising and Evaluating Innovative Learning Environments (pp. 39-65). Leiden: Brill-Sense Publishers.

$\rightarrow$ Craft, A. (2008). Studying collaborative creativity: Implications for education, Thinking Skills and Creativity, 3(3), 241-245.

$\rightarrow$ Day, C. (2012). New Lives of Teachers, Teacher Education Quarterly, 39(1), 7-26.

$\rightarrow$ Deed, C. (2015). A Model of Teacher Adaptation to Open-Plan Settings. In: V. Prain et al. (eds.), Personalising Learning in Open-Plan Schools (pp. 27-41). Rotterdam: Sense Publishers. 
$\rightarrow$ Donaldson, G. (2011). Teaching Scotland's Future: Report of a Review of Teacher Education in Scotland. Edinburgh: The Scottish Government.

$\rightarrow$ Dooner, A.-M., Mandzuk, D., Obendoerfer, P., Babiuk, G., Cerqueira-Vassallo, G., Force, V., Vermette, M. and Roy, D. (2010). Examining Student Engagement and Authority: Developing Learning Relationships in the Middle Grades, Middle School Journal, 41(4), 28-35.

$\rightarrow$ Education Scotland (2020). What is Curriculum for Excellence?, https://education.gov.scot/education-scotland/scottish-education-system/ policy-for-scottish-education/policy-drivers/cfe-building-from-the-statementappendix-incl-btc1-5/what-is-curriculum-for-excellence

$\rightarrow$ Firestone, W. A., Martinez, M.C. (2007). Districts, Teacher Leaders, and Distributed Leadership: Changing Instructional Practice, Leadership and Policy in Schools, 6(1), 3-35.

$\rightarrow$ Fisher, R. and Webb, K. (2006). Subject specialist pedagogy and initial teacher training for the learning and skills sector in England: the context, a response and some critical issues, Journal of Further and Higher Education, 30(4), 337-349.

$\rightarrow$ Fletcher, E. C., Warren, N. Q. and Hernández-Gantes, V. M. (2018). Preparing High School Students for a Changing World: College, Career, and Future Ready Learners, Career and Technical Education Research, 43(1), 77-97.

$\rightarrow$ Fox, K. (2010). "Belonging" as a subject specialist: challenging the barriers, Teacher Education Advancement Network Journal, 1(2), 1-16.

$\rightarrow$ Graesser, A. C., Kuo, B.-C. and Liao, C.-H. (2017). Complex Problem Solving in Assessments of Collaborative Problem Solving, Journal of Intelligence, 5(2), $1-14$.

$\rightarrow$ Griffin, P., Care, E. and McGaw, B. (2012). The Changing Role of Education and Schools. In: P. Griffin, B. McGaw, E. Care (eds.), Assessment and Teaching in $21^{\text {st }}$ Century Skills (pp. 1-15). Dordrecht: Springer.

$\rightarrow$ Havnes, A. (2009). Talk, planning and decision-making in interdisciplinary teacher teams: a case study, Teachers and Teaching: Theory and Practice, 15(1), 155-176.

$\rightarrow$ Hayden, C. and Pike, S. (2005). Including "positive handling strategies" within training in behaviour management: the "Team-Teach" approach, Emotional and Behavioural Difficulties, 10(3), 173-187.

$\rightarrow$ Heider, K. (2005). Teacher Isolation: How Mentoring Programs Can Help, Current Issues in Education, 8(14), 1-7.

$\rightarrow$ Hobbs, L. (2012). Examining the aesthetic dimensions of teaching: Relationships between teacher knowledge, identity and passion, Teaching and Teacher Education, 28(5), 718-727.

$\rightarrow$ John, P. D. (2006). Lesson planning and the student teacher: re-thinking the dominant model, Journal of Curriculum Studies, 38(4), 483-498. 
$\rightarrow$ Jones, M., Michael, C., Mandala, J. and Colachico, D. (2008). Collaborative Teaching: Creating a Partnership between General and Special Education, The International Journal of Learning, 15(7), 203-207.

$\rightarrow$ Kennedy, A. (2016). Professional learning in and for communities: seeking alternative discourses, Professional Development in Education, 42(5), 667-670.

$\rightarrow$ Kyriacou, C. and Kunc, R. (2007). Beginning teachers' expecations of teaching, Teaching and Teacher Education, 23, 1246-1257.

$\rightarrow$ Lahtero, T. J., Lång, N. and Alava, J. (2017). Distributed leadership in practice in Finnish schools, School Leadership \& Management, 37(3), 217-233.

$\rightarrow$ Levi, F. (2010). How technology changes demands for human skills (OECD Education Working Paper No. 45), www.oecd.org/education/skills-beyondschool/45052661.pdf

$\rightarrow$ Lim, F. V., O'Halloran, K.L. and Podlasov, A. (2012). Spatial pedagogy: mapping meanings in the use of classroom space, Cambridge Journal of Education, 42(2), 235-251.

$\rightarrow$ Little, A. and Hoel, A. (2011). Interdisciplinary Team Teaching: An Effective Method to Transform Student Attitudes, Journal of Effective Teaching, 11(1), 36-44.

$\rightarrow$ McManus, J.E. (2010). Social identity and ability grouping in a secondary school. [Doctoral Thesis, Institute of Education]. University of London, https://ethos.bl.uk/ orderdetails.do?uin=uk.bl.ethos.534896

$\rightarrow$ Mulcahy, D. and Morrison, C. (2017). Re/assembling "innovative" learning environments: Affective practice and its politics, Educational Philosophy and Theory, 49(8), 749-758.

$\rightarrow$ Musanti, S. I. and Pence, L. (2010). Collaboration and Teacher Development: Unpacking Resistance, Constructing Knowledge, and Navigating Identities, Teacher Education Quarterly, 37(1), 73-89.

$\rightarrow$ OECD (2013). Innovative Learning Environments. DOI: 10.1787/9789264203488en

$\rightarrow$ Osborn, M. and McNess, E. (2005). The Cultural Context of Teachers' Work: Policy, Practice and Performance. In: N. Bascia, A. Cumming, A. Datnow, K. Leithwood, D. Livingstone (eds.), International Handbook of Educational Policy. Springer International Handbooks of Education (pp. 507-525), Dordrecht: Springer.

$\rightarrow$ Owen, S. (2015). Teacher Professional Learning Communities in Innovative Contexts: "Ah Hah Moments", "Passion" and "Making a Difference" for Student Learning, Professional Development in Education, 41(1), 57-74.

$\rightarrow$ Paris, L.F. (2013). Reciprocal Mentoring: Can it Help Prevent Attrition for Beginning Teachers?, Australian Journal of Teacher Education, 38(6), 136-158. 
$\rightarrow$ Park, S. and Oliver, J. S. (2008). Revisiting the Conceptualisation of Pedagogical Content Knowledge (PCK): PCK as a Conceptual Tool to Understand Teachers as Professionals, Research in Science Education, 38(3), 261-284.

$\rightarrow$ Priestley, M. (2011). Schools, teachers, and curriculum change: A balancing act?, Journal of Educational Change, 12(1), 1-23.

$\rightarrow$ Robinson, V. M. J. (2008). Forging the links between distributed leadership and educational outcomes, Journal of Educational Administration, 46(2), 241-256.

$\rightarrow$ Rytivaara, A. and Kershner, R. (2012). Co-teaching as a context for teachers' professional learning and joint knowledge construction, Teaching and Teacher Education, 28, 999-1008.

$\rightarrow$ Santoyo, C. and Zhang, S. (2016). Secondary Teacher Candidates' Lesson Planning Learning, Teacher Education Quarterly, 43(2), 3-27.

$\rightarrow$ Savage, J. (2012). Moving beyond subject boundaries: four case studies of crosscurricular pedagogy in secondary schools, International Journal of Educational Research, 55, 79-88.

$\rightarrow$ Stets, J. E. and Burke, P. (2000). Identity Theory and Social Identity Theory, Social Psychology Quarterly, 63(3), 224-237.

$\rightarrow$ Stewart, C. (2014). Transforming Professional Development to Professional Learning, Journal of Adult Education, 43(1), 28-33.

$\rightarrow$ Stolle, E. P. and Frambaugh-Kritzer, C. (2014). Putting Professionalism Back into Teaching: Secondary Preservice and In-Service Teachers Engaging in Interdisciplinary Unit Planning, Action in Teacher Education, 36(1), 61-75.

$\rightarrow$ The Scottish Government (2007). Building Excellence: Exploring the Implications of the Curriculum for Excellence for School Buildings. Edinburgh: The Scottish Government.

$\rightarrow$ The Scottish Government (2009). Building Better Schools: Investing in Scotland's Future. Edinburgh: The Scottish Government.

$\rightarrow$ Thousand, J., Villa, R.A. and Nevin, A. (2006). The Many Faces of Collaborative Planning and Teaching, Theory Into Practice, 45(3), 239-248.

$\rightarrow$ Tschannen-Moran, M., Woolfolk Hoy, A. and Hoy, W. K. (1998). Teacher Efficacy: Its Meaning and Measure, Review of Educational Research, 68(2), 202-248.

$\rightarrow$ Vangrieken, K., Dochy, F., Raes, E., Kyndt, E. (2015). Teacher collaboration: A systematic review, Educational Research Review, 15(15), 17-40.

$\rightarrow$ Woolfolk, A., Hoy, W. (1990). Prospective Teachers' Sense of Efficacy and Beliefs about Control, Journal of Educational Psychology, 82(1), 81-91.

$\rightarrow$ Young, F., Cleveland, B., Imms, W. (2019). The affordances of innovative learning environments for deep learning: educators' and architects' perceptions, Australian Educational Researcher, 46(5), 1-28. 